\title{
Dysfunctional breathing in children with asthma: a rare but relevant comorbidity
}

\author{
Eric P. de Groot*, Eric J. Duiverman" and Paul L.P. Brand**
}

ABSTRACT: Hyperventilation and other clinical manifestations of dysfunctional breathing have been reported in childhood, but the prevalence is unknown. In adults, dysfunctional breathing may be a relevant comorbidity in asthma. We aimed to determine the prevalence of dysfunctional breathing in children with asthma and its impact on asthma control.

We performed a cross-sectional survey in 203 asthmatic children (aged 5-18 years), using the Nijmegen Questionnaire and the paediatric Asthma Control Questionnaire.

Dysfunctional breathing was found in 11 (5.3\%) children; more females (eight (12.9\%) out of 62) than males (three $(2.1 \%)$ out $144, p=0.002)$. There was a dose-dependent relationship between increasing Nijmegen Questionnaire scores (increased risk of dysfunctional breathing) and poorer asthma control. Poor asthma control was more common in patients with dysfunctional breathing (10 (90.9\%) out of 11 children) than in children without (65 (32.3\%) out of 192 children; OR 19.3, 95\% Cl 3.14-430.70; $p<0.0001$ ). The median Asthma Control Questionnaire in children with dysfunctional breathing was higher (median (range) 2.00 (1.50-3.17)) than in children without (0.50 (0.17-1.17); $p<0.001)$.

The prevalence of dysfunctional breathing in children and adolescents referred to a hospitalbased paediatric asthma clinic for severe or difficult-to-control asthma is $5 \%$. The association between dysfunctional breathing and asthma control suggests that this may be a clinically relevant comorbidity in paediatric asthma.

KEYWORDS: Asthma control, comorbidity, dysfunctional breathing, paediatric asthma

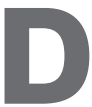
ysfunctional breathing has been defined as chronic or recurrent changes in breathing pattern, causing respiratory and nonrespiratory complaints [1]. Symptoms of dysfunctional breathing include dyspnoea with normal pulmonary function, deep sighing, chest pain, chest tightness, frequent yawning, hyperventilation and breathlessness during exercise $[2,3]$. The severity of these symptoms may range from mild and hardly obtrusive to full-blown attacks of severe hyperventilation and panic [3].

Although cases of hyperventilation and other clinical manifestations of dysfunctional breathing have been reported in childhood [4-9], the prevalence of dysfunctional breathing in children is unknown. Studies in adults have shown that: 1) dysfunctional breathing may be a relevant comorbidity in (difficult) asthma; 2) almost onethird of asthmatic adults have symptoms of dysfunctional breathing; and 3) treatment for dysfunctional breathing helps in improving asthma control in these patients [2]. To our knowledge, there are no studies examining the prevalence of dysfunctional breathing in asthmatic children and adolescents. We designed this study to examine the prevalence of symptoms of DB in school-aged children and adolescents with asthma, and to assess its association with asthma control.

\section{METHODS}

\section{Study population}

Between June 2008 and June 2009, consecutive children and adolescents visiting the Princess Amalia clinic (Zwolle, the Netherlands) for a scheduled follow-up visit for asthma were approached for participation in this cross-sectional questionnaire-based survey. Inclusion was continued over a full 1-year period. The diagnosis and management of asthma follows Global Imitative for Asthma (GINA) guidelines [10, 11].

\section{Inclusion and exclusion criteria}

Inclusion criteria were: 1) diagnosis of asthma, made by a paediatrician according to international guidelines [10]; 2) maintenance therapy with
AFFILIATIONS

*Princess Amalia Children's Clinic, Isala Klinieken, Zwolle,

\#Beatrix Children's Hospital, University Medical Centre,

Groningen, and

"UMCG Postgraduate School of Medicine, University Medical Centre Groningen, Groningen, The Netherlands.

\section{CORRESPONDENCE}

E.P. de Groot

Isala Klinieken

Dokter van Heesweg 2

8025 AB Zwolle

The Netherlands

E-mail: e.p.de.groot@isala.nl

Received:

Aug 202012

Accepted after revision:

Sept 162012

First published online:

Sept 272012 
inhaled corticosteroids (or combination therapy) for at least 3 months before the study; 3 ) the ability to perform reproducible lung function testing; and 4) proper understanding of the Dutch language. Children with serious bronchopulmonary, neuromuscular or cardiovascular comorbidity were excluded.

\section{Nijmegen Questionnaire}

The Nijmegen Questionnaire (NQ) was used to screen patients for the presence of symptoms suggestive of dysfunctional breathing (table 1) [12]. The NQ consists of 16 questions on symptoms of dysfunctional breathing. For each item, the respondent is asked to rate the occurrence of the symptom on a scale ranging from 0 (never) to 4 (very often). Responses are added to form a total NQ score. A total score of 23 or higher has a sensitivity of $91 \%$ and specificity of $95 \%$ for the diagnosis of symptomatic hyperventilation in adults [12]; a score of 18-23 signifies possible symptomatic hyperventilation. In previous surveys of dysfunctional breathing in adults with asthma, an NQ score $\geqslant 23$ was used to identify dysfunctional breathing $[13,14]$.

\section{Asthma control}

Asthma control was measured by the childhood Asthma Control Questionnaire (ACQ) [15-18]. Children aged $\geqslant 12$ years completed the questionnaires themselves; in children aged $<12$ years, the parents completed the questionnaires. Aggregated ACQ scores $<1.0$ were considered to indicate well-controlled asthma [17].

\section{Pulmonary function and nitric oxide measurement}

Expiratory flow-volume loops were recorded according to European Respiratory Society guidelines [19] on a Jaeger MasterScreen (Jaeger, Houston, TX, USA). The forced expiratory volume in $1 \mathrm{~s}$ and forced vital capacity were recorded, and expressed as a \% of the predicted reference value [20]. Exhaled nitric oxide fraction $(F \mathrm{eNO})$ was measured using the NIOX MINO device (Aerocrine, Solna, Sweden), according to standardised guidelines [21] and expressed in parts per billion.

TABLE 1 Symptoms suggestive of dysfunctional
breathing: the Nijmegen Questionnaire
Chest pain
Feeling tense
Blurred vision
Dizziness
Confusion or loss of touch with reality
Fast or deep breathing
Shortness of breath
Tightness across chest
Bloated sensation in stomach
Tingling in fingers and hands
Difficulty in breathing or taking a deep breath
Stiffness or cramps in fingers or hands
Tightness around the mouth
Cold hands or feet
Palpitations in the chest
Anxiety

\section{Specific IgE to inhaled allergens}

Data on aero-allergen sensitisation were recorded from the chart if it had been obtained no longer than 2 years before the patient entered the study. The ImmunoCap system (Pharmacia Diagnostics, Uppsala, Sweden) was used for specific IgE assessments. Sensitisation was defined as a specific $\operatorname{IgE}$ concentration $\geqslant 0.35 \mathrm{kU} \cdot \mathrm{L}^{-1}$. A positive specific IgE test for any of the five major aero-allergens for children in the Netherlands (house dust mite, tree and grass pollen, cat and dog dander) was considered to reflect aero-allergen sensitisation.

\section{Statistical analysis}

SPSS 15.0 (SPSS Inc, Chicago, IL, USA) was used to analyse the data using t-tests to compare means and Chi-squared tests to compare proportions. NQ score, FeNO levels and ACQ scores were assessed by nonparametric methods because of their nonnormal distributions. Total IgE levels were log-transformed before analysis.

\section{RESULTS}

A total of 206 children and their parents were included in the survey. None of the approached parents and children declined participation. Characteristics of the 206 patients are presented in table 2. Most patients had well-controlled asthma with normal lung function, as reported previously in studies from our clinic $[22,23]$, and in studies from similar settings.

\section{Prevalence of dysfunctional breathing}

The response to the individual items in the NQ is presented in table 3. The frequency distribution of total NQ scores is presented in figure 1 . Of the 206 patients, 11 (5.3\%) had NQ scores $\geqslant 23$, indicating dysfunctional breathing, and 18 (8.7\%) had NQ scores of 18-23 (possible dysfunctional breathing). Females were more likely to have dysfunctional breathing (NQ score $\geqslant 23$, eight $(12.9 \%)$ out of 62$)$ than males (three $(2.1 \%)$ out of $144 ; \mathrm{p}=0.002)$. There was no significant difference in age between children with NQ scores $\geqslant 23$ (mean \pm SD $11.7 \pm 4.7$ years) and those with NQ scores $<23(10.4 \pm 3.7$ years; $\mathrm{p}=0.321)$ The ages of the 11 children

\begin{tabular}{|c|c|c|}
\hline TABLE 2 & \multicolumn{2}{|c|}{$\begin{array}{l}\text { Demographic and clinical characteristics of the } \\
206 \text { study participants }\end{array}$} \\
\hline \multicolumn{2}{|l|}{ Female } & $62(30.1)$ \\
\hline \multicolumn{2}{|l|}{ Age years } & $10.4 \pm 3.7$ \\
\hline \multicolumn{2}{|l|}{$\mathrm{BMI} \mathbf{k g} \cdot \mathrm{m}^{-2}$} & $17.2 \pm 3.1$ \\
\hline \multicolumn{2}{|c|}{ Asthma maintenance therapy } & $195(94.7)$ \\
\hline \multicolumn{2}{|c|}{$\mathrm{ICS}^{\#} \leqslant 250 \mu \mathrm{g} \cdot \mathrm{day}^{-1}$} & 143 \\
\hline \multicolumn{2}{|c|}{ ICS $251-500 \mu \mathrm{g} \cdot$ day $^{-1}$} & 44 \\
\hline \multicolumn{2}{|c|}{ ICS $>500 \mu \mathrm{g} \cdot \mathrm{day}^{-1}$} & 1 \\
\hline \multicolumn{2}{|c|}{ Combination therapy ICS+LABA } & 51 \\
\hline \multicolumn{2}{|l|}{ FVC \% pred } & $101.3 \pm 12.0$ \\
\hline \multicolumn{2}{|c|}{ FEV $1 \%$ pred } & $100.3 \pm 14.7$ \\
\hline \multicolumn{2}{|l|}{ FeNO ppb } & $12.5(0-24)$ \\
\hline \multicolumn{2}{|c|}{ Sensitised to one or more aeroallergens } & $106(51.5)$ \\
\hline
\end{tabular}

Data are presented as $n(\%)$, mean $\pm S D, n$ or median (range). BMI: body mass index; ICS: inhaled corticosteroids; LABA: long-acting $\beta$-agonist; FVC: forced vital capacity; \% pred: \% predicted; FEV1: forced expiratory volume in $1 \mathrm{~s}$; FeNO: exhaled nitric oxide fraction. ${ }^{\#}$ : daily dose of fluticasone (or equivalent). 
TABLE 3 Responses to individual items in the Nijmegen Questionnaire (NQ)

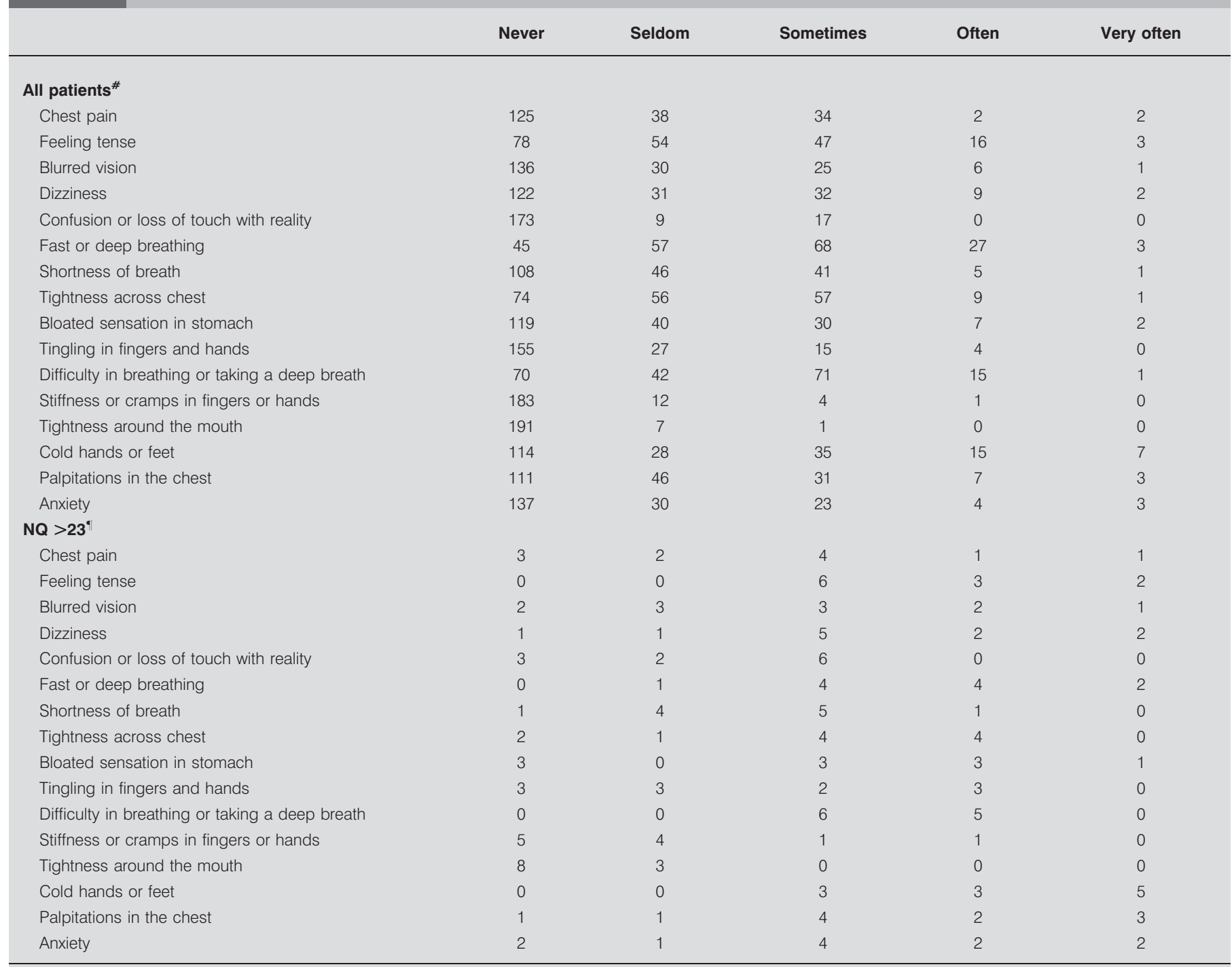

Data are presented as $n{ }^{*}: \mathrm{n}=206 ;{ }^{\bullet}: \mathrm{n}=11$.

with high NQ scores indicating dysfunctional breathing ranged from 5 to 18 years (mean 11.7 years).

\section{Impact on asthma control}

Completed ACQ questionnaires were obtained in 203 (98.5\%) children. Overall, asthma was well controlled in the study population, with $128(63.1 \%)$ children having an ACQ score $<1.0$, indicating fully controlled asthma. The relationship between NQ scores and ACQ scores is presented in figure 2. There was a dose-dependent relationship between increasing NQ scores (increased risk of dysfunctional breathing) and poorer asthma control, despite the limited variability in ACQ scores. Poor asthma control (ACQ $>1)$ was significantly more common in patients with NQ scores $\geqslant 23$ (10 (90.9\%) out of 11 children) than in children with an NQ score $<23$ (65 (32.3\%) out of 192; OR 19.3, 95\% CI 3.14-430.70; $<<0.0001)$. The median ACQ in children with an NQ score $\geqslant 23$ was higher (median (range) $2.00(1.50-3.17)$ ) than in children with an NQ score $<23$ (0.50 (0.17-1.17); $\mathrm{p}<0.001)$ (fig. 1).
Relationship of NQ scores to pulmonary function, FeNO levels and aeroallergen sensitisation

There were no significant differences in sex, pulmonary function, FeNO and sensitisation to aero-allergens between patients with low, intermediate and high NQ scores (table 4).

\section{DISCUSSION}

In this large sample of paediatric outpatients with chronic persistent asthma, 5\% of patients had symptoms suggestive of dysfunctional breathing on the NQ. This prevalence of dysfunctional breathing in children with asthma is much lower than that reported in adults in previous similar surveys $(29 \%)$ [14]. Despite the low prevalence of dysfunctional breathing in children and adolescents with asthma, our survey did show a significant and clinically relevant negative association between dysfunctional breathing and asthma control (fig. 2). This suggests, therefore, that screening for dysfunctional breathing as a significant comorbidity may be 


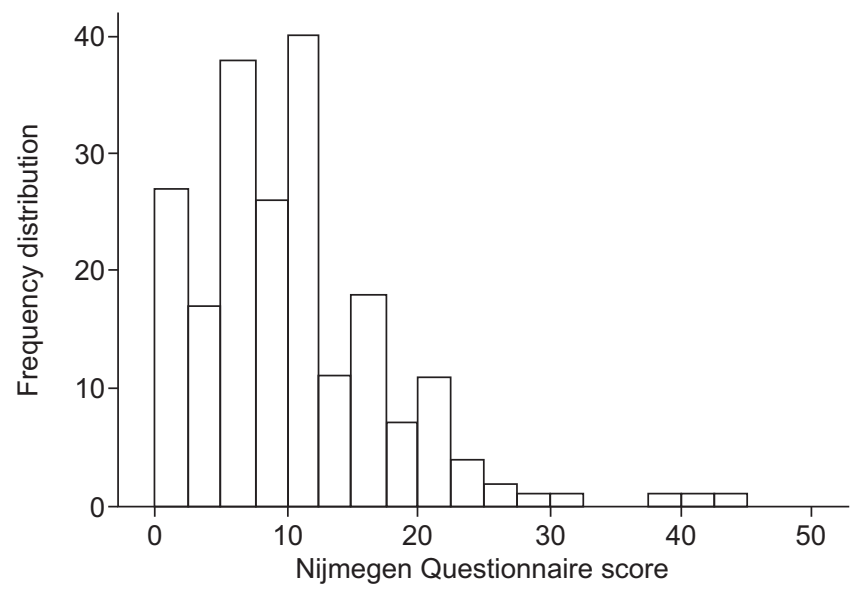

FIGURE 1. Frequency distribution of Nijmegen Questionnaire total scores.

justified in children and adolescents with asthma, in particular when asthma is poorly controlled [24, 25].

To our knowledge this is the first study examining the prevalence of dysfunctional breathing in children and adolescents with asthma. In adults, dysfunctional breathing has been studied more extensively. In general population samples of adults, prevalence rates of dysfunctional breathing of $6-10 \%$ have been reported [26, 27]. In a UK primary care practice, in a random sample of 300 adults with asthma, 29\% had scores $\geqslant 23$ on the NQ [13]. In agreement with our study, dysfunctional breathing was more common in females than in males. In contrast to the previous studies in adults, which were conducted in general practice, our population was recruited in a specialised hospital-based paediatric asthma clinic, in which patients can only be seen after referral by their primary care practitioner. It is likely, therefore, that the population of children and adolescents recruited for this study represents a more severe or difficult-to-control group of asthmatic patients than the groups of patients in previous studies in adults who were recruited from primary care practices. Even in this group of children and adolescents with relatively severe or difficult to treat asthma, dysfunctional breathing was rare. Together with the rarity of published data on dysfunctional breathing in children, this observation strongly suggests that dysfunctional breathing is rarer in children than in adults with asthma.

Despite its relatively low prevalence, however, there was a strong and dose-dependent association between dysfunctional

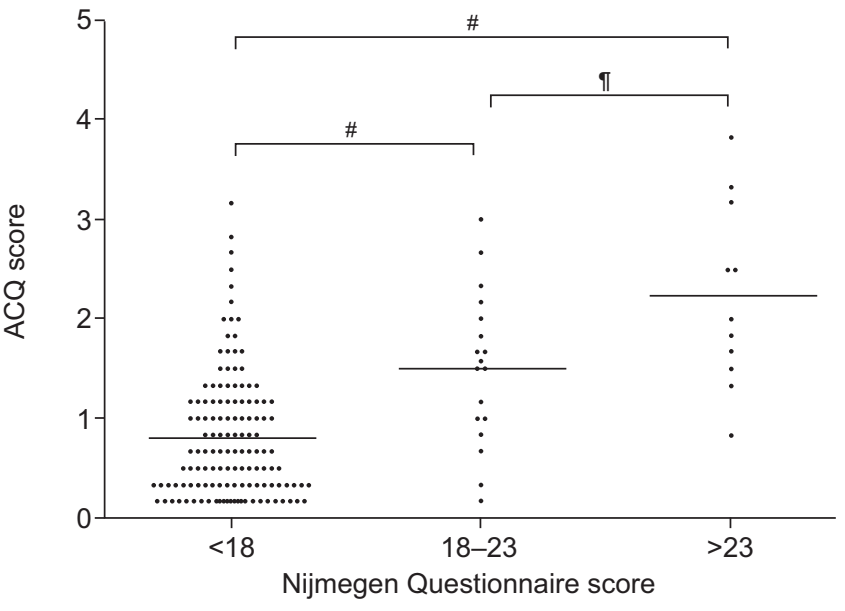

FIGURE 2. Asthma Control Questionnaire (ACQ) score for the different groups of Nijmegen Questionnaire Score. <18: no dysfunctional breathing; 18-23: possible dysfunctional breathing; $>23$ : dysfunctional breathing. ${ }^{*}$ : $p<0.0001$; थ: $p=0.056$.

breathing and asthma control in our study (fig. 2). Due to the cross-sectional nature of our study, it is impossible to draw firm conclusions as to the causal nature of this association. There is overlap between symptoms of dysfunctional breathing (table 1) and those of asthma, with symptoms such as shortness of breath, chest tightness, impossibility of deep breathing and rapid breathing. It could, therefore, be argued that increased NQ scores are merely a marker of more severe or more poorly controlled asthma. The symptoms of fast or deep breathing, difficulty in breathing or taking a deep breath, and tightness across chest were indeed frequently reported by patients with NQ scores $>23$, but shortness of breath was not (table 3). Because physiotherapy for dysfunctional breathing in adult asthmatics not only reduces dysfunctional breathing symptoms but also improves their asthma, identifying and treating dysfunctional breathing in adults is clinically worthwhile. Our results, showing an association of dysfunctional breathing to poor asthma control in children, suggest that identifying and treating dysfunctional breathing in asthmatic children is worth pursuing as well.

Treatment of dysfunctional breathing is directed at relaxation and re-institution of normal breathing pattern, by means of breathing retraining techniques under supervision of a physiotherapist $[2,28]$. In adult asthmatics, such treatment

TABLE 4 Relationship of Nijmegen Questionnaire (NQ) scores to sex, pulmonary function and aero-allergen sensitisation

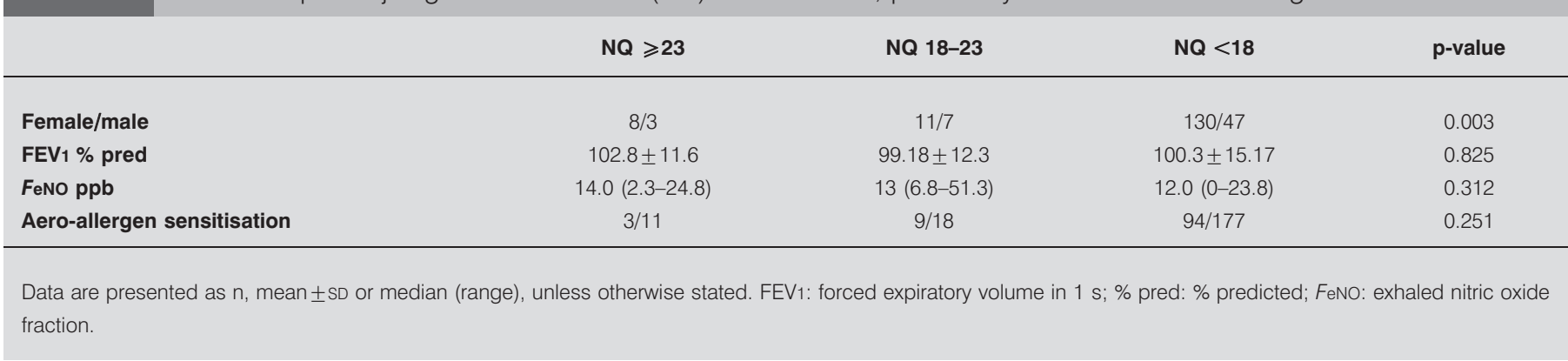


with brief physiotherapy intervention improves symptoms of dysfunctional breathing, reduces impairment by breathing problems in daily life and, when exercising, increases both generic and disease-specific quality of life, and reduces the number of emergency visits for asthma [2, 28]. These improvements were maintained in many patients 6 months after the intervention [2]. No such studies have been performed in children and adolescents. Our clinical experience suggests that breathing retraining in paediatric patients with asthma and symptoms of dysfunctional breathing is beneficial in reducing complaints [3].

The primary strength of our study is that it is the first to examine the presence of dysfunctional breathing in children with asthma, and its association with asthma control. Similar to earlier studies on dysfunctional breathing, the main limitation of our study is the lack of a gold standard for dysfunctional breathing. In adults, the NQ has been used as a screening tool for dysfunctional breathing, although it was originally developed as a questionnaire for hyperventilation, which, although part of the dysfunctional breathing spectrum, is not identical to dysfunctional breathing [3]. The NQ has not been validated in children. Clinical descriptions of dysfunctional breathing in children have reported symptoms such as deep sighing or excessive yawning that are not captured in the NQ [29]. In addition, the NQ has only been developed as a screening tool for the diagnosis of hyperventilation, not as an instrument to assess the severity of dysfunctional breathing symptoms [30]. When asthma is not well controlled, especially in exercise, and the asthma treatment is optimised without improvement of asthma symptoms, dysfunctional breathing should be considered as a comorbidity. Awaiting further validation, the NQ may be used for such screening purposes. Exercise-induced shortness of breath without wheeze appears to be the most common presenting symptom of dysfunctional breathing in children $[3,8,9]$. Visual inspection of breathing pattern during exercise by paediatric physical therapists may also help in recognising dysfunctional breathing [3].

Further studies are therefore needed to develop and validate a screening instrument for dysfunctional breathing and its severity in children and adolescents, in particular for those with asthma.

In conclusion, dysfunctional breathing appears to be rare in children and adolescents referred to a hospital-based paediatric asthma clinic for severe or difficult-to-control asthma, with only $5 \%$ of patients reporting an NQ score $\geqslant 23$. However, the strong and dose-dependent association between dysfunctional breathing and asthma control suggests that dysfunctional breathing may be a clinically relevant comorbidity in paediatric asthma, and that identifying and treating dysfunctional breathing in children and adolescents with asthma may be worthwhile. For this purpose, a valid screening instrument for dysfunctional breathing in children is urgently needed.

\section{STATEMENT OF INTEREST}

None declared.

\section{REFERENCES}

1 Morgan MD. Dysfunctional breathing in asthma: is it common, identifiable and correctable? Thorax 2002; 57: Suppl. 2, II31-II35.
2 Thomas M, McKinley RK, Freeman E, et al. Breathing retraining for dysfunctional breathing in asthma: a randomised controlled trial. Thorax 2003; 58: 110-115.

3 de Groot EP. Breathing abnormalities in children with breathlessness. Paediatr Respir Rev 2011; 12: 83-87.

4 Enzer NB, Walker PA. Hyperventilation syndrome in childhood. A review of 44 cases. J Pediatr 1967; 70: 521-532.

5 Baranes T, Rossignol B, Stheneur C, et al. Le syndrome d'hyperventilation pulmonaire chez l'enfant, revue de la littérature. [Hyperventilation syndrome in children.] Arch Pediatr 2005; 12: 1742-1747.

6 Herman SP, Stickler GB, Lucas AR. Hyperventilation syndrome in children and adolescents: long-term follow-up. Pediatrics 1981; 67: 183-187.

7 Brouwer AF, Roorda RJ, van Reijn DA, et al. Inspanningsgebonden benauwdheid bij kinderen: disfunctionele ademhaling? Tijdschr Kindergeneeskd 2004; 72: 209-212.

8 Abu-Hassan M, Tannous B, Weinberger M. Exercise induced dyspnea in children and adolescents: if not asthma then what? Ann Allergy Asthma Immunol 2005; 94: 366-371.

9 Seear M, Wensley D, West N. How accurate is the diagnosis of exercise induced asthma among Vancouver schoolchildren? Arch Dis Child 2005; 90: 898-902.

10 Global strategy for asthma management and prevention. Global Initiative for Asthma (GINA) 2012. Available from: www. ginasthma.org

11 Pedersen SE, Hurd SS, Lemanske RF Jr, et al. Global strategy for the diagnosis and management of asthma in children 5 years and younger. Pediatr Pulmonol 2011; 46: 1-17.

12 van Dixhoorn DJ, Duivenvoorden HJ. Efficacy of Nijmegen Questionnaire in recognition of the hyperventilation syndrome. J Psychosom Res 1985; 29: 199-206.

13 Thomas M, McKinley RK, Freeman E, et al. Prevalence of dysfunctional breathing in patients treated for asthma in primary care: cross sectional survey. BMJ 2001; 322: 1098-1100.

14 Thomas M, McKinley RK, Freeman E, et al. The prevalence of dysfunctional breathing in adults in the community with and without asthma. Prim Care Respir J 2005; 14: 78-82.

15 Juniper EF, Guyatt GH, Cox FM, et al. Development and validation of the Mini Asthma Quality of Life Questionnaire. Eur Respir J 1999; 14: 32-38.

16 Juniper EF, Gruffydd-Jones K, Ward S, et al. Asthma Control Questionnaire in children: validation, measurement properties, interpretation. Eur Respir J 2010; 36: 1410-1416.

17 Juniper EF, Bousquet J, Abetz L, et al. Identifying "wellcontrolled" and "not well-controlled" asthma using the Asthma Control Questionnaire. Respir Med 2006; 100: 616-621.

18 O'Byrne PM, Pedersen S, Busse WW, et al. Effects of early intervention with inhaled budesonide on lung function in newly diagnosed asthma. Chest 2006; 129: 1478-1485.

19 Quanjer PH, Tammeling GJ, Cotes JE, et al. Lung volumes and forced ventilatory flows. Report Working Party Standardization of Lung Function Tests, European Community for Steel and Coal. Official Statement of the European Respiratory Society. Eur Respir J 1993; 6: Suppl. 16, 5-40.

20 Stanojevic S, Wade A, Stocks J, et al. Reference ranges for spirometry across all ages: a new approach. Am J Respir Crit Care Med 2008; 177: 253-260.

21 American Thoracic Society/European Respiratory Society. ATS/ ERS recommendations for standardized procedures for the online and offline measurement of exhaled lower respiratory nitric oxide and nasal nitric oxide, 2005. Am J Respir Crit Care Med 2005; 171: 912-930.

22 Baatenburg de JA, Brouwer AF, Roorda RJ, et al. Normal lung function in children with mild to moderate persistent asthma well controlled by inhaled corticosteroids. J Allergy Clin Immunol 2006; 118: 280-282. 
23 de Groot EP, Nijkamp A, Duiverman EJ, et al. Allergic rhinitis is associated with poor asthma control in children with asthma. Thorax 2012; 67: 582-587.

24 Bush A, Hedlin G, Carlsen KH, et al. Severe childhood asthma: a common international approach? Lancet 2008; 372: 1019-1021.

25 de Groot EP, Duiverman EJ, Brand PL. Comorbidities of asthma during childhood: possibly important, yet poorly studied. Eur Respir J 2010; 36: 671-678.

26 Lum LC. Hyperventilation: the tip and the iceberg. J Psychosom Res 1975; 19: 375-383.
27 Rice RL. Symptom patterns of the hyperventilation syndrome. Am J Med 1950; 8: 691-700.

28 Hagman C, Janson C, Emtner M. Breathing retraining - a five-year follow-up of patients with dysfunctional breathing. Respir Med 2011; 105: 1153-1159.

29 Prys-Picard CO, Kellett F, Niven RM. Disproportionate breathlessness associated with deep sighing breathing in a patient presenting with difficult-to-treat asthma. Chest 2006; 130: 1723-1725.

30 Prys-Picard CO, Niven R. Dysfunctional breathing in patients with asthma. Thorax 2008; 63: 568 